\title{
The Impacts of Positive Psychology and Individualism on Mental Health Status of the Elderly in China: Evidence From Chinese General Social Survey Data
}

Yujie Zhang ( $\square$ zhangyujie@sjtu.edu.cn )

Shanghai Jiao Tong University

\section{Research}

Keywords: positive psychology, mental health, individualism, Chinese General Social Survey (CGSS)

Posted Date: December 29th, 2021

DOl: https://doi.org/10.21203/rs.3.rs-1130227/v1

License: (c) (i) This work is licensed under a Creative Commons Attribution 4.0 International License. Read Full License 


\section{Abstract \\ Background}

Many previous studies have proved that positive psychology can promote mental health. However, little is known about how and when it promotes mental health in older adults.

\section{Methods}

The data of this study were sourced from the 2017 wave of Chinese General Social Survey (CGSS), involving 1,537 older adults aged 60 and above. OLS regression model was used to explore the impact of positive psychology on mental health of the elderly. Moreover, stata 16.0 was used to measure the moderating effect of individualism on the relationship between positive psychology and mental health.

\section{Results}

After controlling for demographic characteristics, socio-economic status and lifestyle factors, the regression results suggest that positive psychology was associated with mental health (coefficient $=0.112, p<0.01$ ). In addition, the positive relationship was significantly stronger for people who were older, married, lived in urban areas, with higher education and higher subjective social class position, and higher exercise frequency. Moreover, the moderating effect analysis results suggest that individualism strengthened the relationship between positive psychology and mental health.

\section{Conclusions}

This study reveals that positive psychology has a positive effect on mental health among the elderly, and the positive health effect shows significant age, marital status, living areas, education background, social class position and physical exercise inequalities. Furthermore, this study also provides new evidence indicating that individualism positively moderates the relationship between positive psychology and mental health. Promoting positive psychology can be a promising way for China to promote psychological care for the elderly in the future.

\section{Background}

In recent years, with the increasing number of elderly populations, their health problems have attracted more and more attention. It is not only the basic physical health that affects the quality of life and health level of the elderly, but also mental health is becoming an important factor [1]. If the spiritual needs of the elderly are not met, it will produce loneliness, depression, and accelerate the physical and psychological aging of the elderly. Mental health problems will induce depression, Alzheimer's disease, and other psychological diseases [2,3]. In serious cases, mental health problems may even increase the risk that older adults would attempt or commit suicide. As older adults retire, they have less social participation, and their spiritual needs will be more difficult to be satisfied socially. At present, the common psychological problems of the elderly include anxiety, depression, hypochondriasis, obsessive-compulsive disorder, diet and sleep disorder, cognitive disorder, interpersonal sensitivity, alcohol dependence and so on [4]. If the government does not intervene, those mental health problems can lead to serious consequences for the whole society.

Previous studies have found that mental health status of the elderly is related to emotional sensitivity factors, but few studies pay attention to the impact of positive psychology from a holistic view on the mental health of the elderly [5-7]. China's increasing urbanization has not only brought convenience to the elderly, but also brought great challenges. These challenges are like the socio-cultural challenges experienced by Americans at the beginning of 20th century. At the beginning of 20th century, American historian James Adams first created the word "American Dream" in Epic of America, which is based on this background. In 2013, China also put forward the "Chinese dream". These dreams are the highest needs of human psychological 
development and the spiritual pillar of unity, encouragement, and support for social progress [8]. The connection between the Chinese dream and the American dream is the positive psychology behind the national dreams. The importance of positive psychology to China is not only the promotion of history, the inevitable requirement of development, the voice of the Chinese people, but also the responsibility of China's healthy aging.

\section{Literature review}

Compared with positive emotions, commitment, relationships and achievements, there were few studies on the impact of positive psychology on the mental health of the elderly. Like achievements, positive psychology is a promoting factor, which will make the elderly more resilient when facing difficulties in life [9-11]. Scholars have explored the impact of positive psychology on mental health among people. The theoretical basis of positive psychology is Darwin's theory of evolution. In his theory of evolution, Darwin pointed out that human psychology is the result of long evolutionary history. Natural selection and sexual selection are the main evolutionary processes that produce these psychological mechanisms. The meaning of the selected psychological mechanism is to be conducive to human survival and reproduction. Human evolutionary choice makes human beings have positive nature, empathy, self-control, moral sense, and reason, like learning, love creation, good at imagination and willing to plan the future. It also makes human beings have love, a sense of responsibility, understand communication and cooperation, have the ability of aesthetic and image thinking, and improve their mental health status $[12,13]$. Furthermore, humans have one of the oldest nerve channels, called the vagus nerve. The vagus nerve governs most of the organs of the respiratory and digestive systems, as well as the feeling, movement, and gland secretion of the heart. The new research of positive psychology has found that the vagus nerve is related to prosocial behavior, morality, and positive experience of happiness [14-16]. Research on the elderly found that when people see noble and beautiful things, they will feel a positive force because of the opening of the vagus nerve [17]. Moreover, a study argued that when people are positive, their self-identity will be improved and they will be more willing to design and pursue life goals, so that their intellectual resources will be improved and their ability to solve problems, think about problems and create problems will be strengthened [18]. The study of Song et al. (2019) focused on the efficacy of psychological capital intervention (PCl) for depression from the perspective of positive psychology supported this conclusion [19]; the scholars agreed that positive psychology makes people produce positive emotions, including pride, calm, gratitude, satisfaction, interest, pleasure, hope, curiosity, and love. Positive emotion is an important ability that can help improve people's quality of life and happiness index. It is a valuable renewable resource. In addition, some studies summarized the moderating role of personal value between positive psychology and mental health [20,21].

In Chinese society, after economic reform in 1978, the fierce competition of the free market economy to a large extent urged the individual atomized [22]. These individuals have lost the protection of the original planned economic unit system, and all social problems have been transformed into personal viability and let individuals bear these problems alone. In the 1980s, personal independence was once a liberation force admired by everyone, but now it has become a huge pressure that vulnerable individuals can't bear. After the mid-1990s, when the individualism ideology began to envelop the market, it also participated in the re-shaping of people, which made people equip with more independent consciousness [23]. Entering the 21st century, with the development of urbanization and the development of socialist market economy with Chinese characteristics, individualism has become an irreversible trend in Chinese society

Individualism can positively or negatively regulate the relationship between positive psychology and mental health. On the one hand, individualism can play a negative regulatory role. Under the catalysis of individualism, due to the lack of responsibilities and obligations for the public interest, individuals have no sense of belonging to the community. Especially for people born in and after 1980s, economic reform has made them realize that personal interests had priority over collective interests, and they can't find an organic connection with public life and public community, so they can't bear the corresponding responsibilities required by society, which may lead to their lack of positive psychology and reduce their mental health [24]. Besides, individualism may degenerate into more and more intense anxiety. The emergence of solipsistic individualism is related to the disappearance of certainty and security. When various communities acting as protectors are dissolved, people may lose their sense of security, and this will damage their mental health status [25]. On the other hand, individualism plays a different role for people born in 1960s and before. These people are the elderly in China. They experienced famine and poverty in the collectivist period. Individualism brings them hope that people can actively pursue life happiness. Economic reform in 1980s made them 
more aware that Individualism can play a positive role of initiative and participation in personal life and social interaction. This also means that individualism promotes people's own welfare [26]. In Chinese context, old people with individualism have a more positive attitude to face life challenges and have better resilience and mental health status in the transitional society [27]. Therefore, for the elderly in China, individualism is more likely to promote the relationship between positive psychology and mental health.

In summary, as fewer empirical studies have explored the impact of positive psychology on the mental health status of older adults in China, in the context of the rise of individualism. To fulfill this gap, this study aims to explore the relationship between positive psychology and mental health for the elderly in China, using the 2017 wave of Chinese General Social Survey (CGSS) data. The results of this study could shed light on future studies concerning the effect of positive psychology on mental health in transitional society.

\section{Methods}

\section{Data Source}

The data of this study were obtained from the 2017 wave of the Chinese General Social Survey (CGSS). CGSS data are freely available at http://cnsda.ruc.edu.cn/index.php?r=projects/view\&id=94525591. CGSS is a nationally representative longitudinal survey of communities, households, and individuals in China. Since 2003, CGSS has conducted an annual survey on individuals in 125 counties (districts), 500 streets (townships and towns), 1,000 neighborhood (village) committees and 10,000 families in China. By regularly and systematically collecting data from Chinese people and all aspects of Chinese society, CGSS summarizes the long-term trend of social change. The data in the CGSS are de-identified. The actual sample size of this project in 2017 was 12,582. Given the fact that this study investigated the impact of positive psychology on mental health among older population, respondents under 60 were removed. After deleting cases with missing information, a total of 1,533 older adults aged 60 and above were included in this study.

\section{Measures}

\section{Dependent Variable}

In this study, subjective mental health indicators were used to represent mental health status of older adults [28]. For example, positive and negative sensory indicators of mental health are subjective indicators. Subjective indicators are not random imagination but based on statistics. The subjective mental health indicators we selected include positive indicators and negative indicators, which can reflect the health status from a holistic view. In CGSS, older adults were requested to indicate their degree of subjective happiness and depression frequency, respectively. The responses to the two questions range from 1 to 5 , and a higher number suggests a higher degree of mental health status. This study then summed the responses to obtain a mental health score, which ranges from 2 to 10 .

\section{Independent Variable}

Positive psychology mainly refers to a positive psychological attitude or state. It is a positive and stable psychological tendency for individuals to treat themselves, others, or things [29]. When encountering negative things, positive psychology can change people's perspective on problems, cultivate positive thinking skills, and change people's behavior mode [30]. In CGSS, respondents were asked about six related questions, to indicate their positive psychological attitude, including attitude for uncertainty and hope. Each question used a 5-point Likert scale. This study summed these responses to get a positive psychology score, and the total score of the five questions is 6 to 30 points, with a higher score indicating more positive psychology attitude.

\section{Moderating Variable}

Individualism is a political, ethical, and social philosophy that emphasizes personal freedom, personal interests, and self-control [31]. In China, the most individualistic issue is fertility, because China has experienced a period of family planning, and at present, 
birth restrictions are being liberalized. In CGSS, older adults were asked about their liberal attitude towards the number of children. The response ranges from 1 to 5 , with a higher number indicating higher degree of individualism.

\title{
Control Variables
}

Since socio-demographic characteristics and health-related lifestyle factors significantly impacted the mental health of the elderly [32,33]. To reduce the bias of omitted variables, three categories of control variables were used in this study. The first type of control variable describes the demographic characteristics, including four variables: age, gender, marital status and living areas. The second type of control variables describes the socio-economic status, including three variables: education background, income, and subjective social class position. The third type of control variables focuses on health-related lifestyle factors, including four variables: internet use, friend interaction, gathering with relatives, and physical exercise. It worth mentioning that age is a continuous variable, gender is binary variable ("male" $=1$, "female" $=0$ ), marriage is a binary variable ("being in marriage" $=1$, "not in marriage" $=0$ ), living area is a binary variable ("urban" $=1$, "rural" $=0$ ), education background is a binary variable ("above junior high school" $=1$, "junior high school and below" $=0$ ), and income is a binary variable ("above 10,000 RMB per year" $=1$, "below 10,000 RMB per year" $=0$ ). Besides, subjective social class ranges from 1 to 10 , with higher score indicating higher social class position. What's more, internet use, friend interaction, gathering with relatives and physical exercise all ranges from 1 to 5 , with higher score indicating higher frequency.

Furthermore, before the empirical study, the method expansion factor was used to test the main variables. The results showed that the Variance Expansion Factor (VIF) value of independent variables, moderating variables, and control variables were far lower than the critical value of 10 , which further suggested that there was no multicollinearity problem across these regression models.

\section{Methodology}

In accordance with the Grossman's analysis frame [34], this study constructs the following econometric model to analyze the impacts of positive psychology and individualism on mental health:

\section{Mental Health}

\author{
$=\beta_{0}+\beta_{1}$ Positive Psychology $_{i}+\beta_{2}$ Individualism $_{i}$ \\ $+\beta_{3}$ Positive Psychology $_{i} *$ Individualism $_{i}+\beta_{4} C V_{i}+\varepsilon_{i}(i$
}

\section{$=1,2,3 \ldots N)$}

Where $i$ indicates the individual, Mental health ${ }_{i}$ denotes the mental health score for the older adult $i$, $\beta_{0}$ refers to the intercept term, $\beta_{1}, \beta_{2}$ and $\beta_{3}$ are the regression coefficients for positive psychology, individualism, and interaction item, respectively. In addition, $C V_{i}$ stands for the control variables, and $\varepsilon_{i}$ represents the error term.

\section{Results}

\section{Characteristics of the study population}

Table 1 reports the characteristics of the study population. The mean value of mental health, positive psychology, individualism of respondents was 7.615, 21.205, and 2.675, respectively. Furthermore, most respondents were aged around 71.412, and more than half of them were women. Most respondents were married. Half of the respondents lived in urban areas. Most respondents positioned themselves as medium to lower class in society, and they received less than 9 years of education and had income 
less than 10,000 RMB. Moreover, seldom did the respondents use internet, interact with friends or relatives, or do physical exercise.

Table 1

Characteristics of the Study Population

\begin{tabular}{|llllll|}
\hline Variable & Mean & SD & Min & Max & N \\
\hline Mental Health & 7.615 & 1.596 & 2 & 10 & 1,533 \\
\hline Positive Psychology & 21.205 & 3.065 & 6 & 30 & 1,533 \\
\hline Individualism & 2.675 & 1.194 & 1 & 5 & 1,533 \\
\hline Positive Psychology * Individualism & 56.505 & 26.502 & 12 & 140 & 1,533 \\
\hline Demographics & & & & & \\
\hline Age & 71.412 & 7.844 & 60 & 99 & 1,533 \\
\hline Gender & 0.474 & 0.499 & 0 & 1 & 1,533 \\
\hline Marital Status & 0.736 & 0.441 & 0 & 1 & 1,533 \\
\hline Living Area & 0.513 & 0.500 & 0 & 1 & 1,533 \\
\hline Socio-economic Status & & & & 1 & 1,533 \\
\hline Education & 0.488 & 0.500 & 0 & 1 & 1,533 \\
\hline Income & 0.061 & 0.239 & 0 & 1 & 1,533 \\
\hline Social class & 4.010 & 1.743 & 1 & 10 & 1,533 \\
\hline Health-related Lifestyle Factors & & & & 5 & 5 \\
\hline Internet Use & 1.873 & 1.557 & 1 & 5 & 1,533 \\
\hline Friend Interaction & 2.157 & 1.046 & 1 & 5 & 1,533 \\
\hline Gathering with Relatives & 2.092 & 0.766 & 1 & 5 & 1,533 \\
\hline Physical Exercise & 2.521 & 1.731 & 1 & 5 & 1,533 \\
\hline Notes: Positive Psychology * Individualism means the interaction & item of positive psychology and individualism. \\
\hline
\end{tabular}

\section{Overall Regression Results Analysis}

Table 2 shows the overall regression results. The overall regression results suggest that mental health was associated with positive psychology (coefficient $=0.114, p<0.01$ ). This suggests positive psychology can alleviate mental health status among older adults. Furthermore, it was found that being older, married, living in urban areas, having more years of education, positioning in higher social class, and doing more physical exercise were significantly associated with higher mental health status. Moreover, the regression results also indicate that gender, income, internet use, friend interaction and gathering with relatives had no significant impact on mental health status of the elderly. 
Table 2

Overall Regression Results

\begin{tabular}{|c|c|c|c|c|}
\hline Variable & Coefficient & S.E. & $\mathbf{t}$ & $p>|t|$ \\
\hline Positive Psychology & $0.114^{\star \star \star}$ & 0.012 & 9.49 & 0.000 \\
\hline Age & $0.014 * \star \star$ & 0.005 & 2.87 & 0.004 \\
\hline Gender & 0.074 & 0.073 & 1.02 & 0.309 \\
\hline Marital Status & $0.197^{\star \star}$ & 0.087 & 2.28 & 0.023 \\
\hline Living Area & 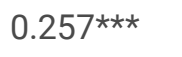 & 0.090 & 2.86 & 0.004 \\
\hline Education & $0.163^{*}$ & 0.088 & 1.84 & 0.066 \\
\hline Income & 0.052 & 0.149 & 0.35 & 0.726 \\
\hline Social Class & 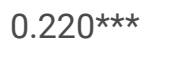 & 0.022 & 10.14 & 0.000 \\
\hline Internet Use & 0.031 & 0.027 & 1.13 & 0.260 \\
\hline Friend Interaction & -0.026 & 0.038 & -0.68 & 0.494 \\
\hline Gathering with Relatives & 0.039 & 0.051 & 0.76 & 0.448 \\
\hline Physical Exercise & $0.145^{\star \star \star}$ & 0.023 & 6.19 & 0.000 \\
\hline Observations & \multicolumn{4}{|l|}{1,533} \\
\hline Notes: ${ }^{* \star *} p<0.01,{ }^{* \star} p<0.0$ & ${ }^{*} p<0.01$ & & & \\
\hline
\end{tabular}

\section{Regression Results In Different Subgroups}

In this section, this study further examined whether the mental health benefit of positive psychology differs by living area and physical exercise. The reason why investigate living area and physical exercise is that age, marital status, and social class have long been proved associated with mental health status. However, fewer studies focused on the heterogeneity of living area and physical exercise, considering China's unique urban-rural differences and physical exercise has recently been promoted as a national strategy, this study chose living area and physical exercise to carry out further regression analysis.

Table 3 illustrates the regression results by living area and physical exercise. The regression results reveal that positive psychology improved mental health for older adults lived in both urban areas (coefficient $=0.099, p<0.01$ ) and rural areas (coefficient $=0.125, p<0.01$ ). Moreover, there was no evidence to suggest that there was statistically significant different for urban and rural older adults. Furthermore, the mental health promoting impact of positive psychology was stronger for the elderly living in rural areas. 
Table 3

Regression Results by Living Area and Physical Exercise

\begin{tabular}{|c|c|c|c|c|c|c|c|}
\hline \multirow[t]{2}{*}{ Variable } & \multicolumn{2}{|l|}{ By Living Area } & \multicolumn{5}{|c|}{ By Physical Exercise } \\
\hline & Urban & Rural & Never & $\begin{array}{l}\text { Several } \\
\text { Times a } \\
\text { Year or Less }\end{array}$ & $\begin{array}{l}\text { Several } \\
\text { Times a } \\
\text { Month }\end{array}$ & $\begin{array}{l}\text { Several } \\
\text { Times a } \\
\text { Week }\end{array}$ & Everyday \\
\hline $\begin{array}{l}\text { Positive } \\
\text { Psychology }\end{array}$ & $\begin{array}{l}0.099 * * \star \\
(5.95)\end{array}$ & $\begin{array}{l}0.125^{\star \star \star} \\
(7.22)\end{array}$ & $\begin{array}{l}0.139 * \star \star \\
(8.00)\end{array}$ & $0.076 *(1.89)$ & $\begin{array}{l}0.196^{\star \star \star} \\
(3.74)\end{array}$ & $\begin{array}{l}0.104^{* * *} \\
(3.32)\end{array}$ & $\begin{array}{l}0.053^{\star \star} \\
(2.12)\end{array}$ \\
\hline Age & $\begin{array}{l}0.014 \text { ** } \\
(2.14)\end{array}$ & $0.014 *(1.74)$ & $\begin{array}{l}0.017 \text { ** } \\
(2.38)\end{array}$ & $0.030(1.52)$ & $-0.015(-0.70)$ & $0.019(1.43)$ & $0.007(0.69)$ \\
\hline Gender & $0.161(1.61)$ & $0.002(00.02)$ & $0.140(1.28)$ & $-0.155(-0.63)$ & $-0.198(-0.60)$ & $-0.073(-0.40)$ & $0.194(1.38)$ \\
\hline $\begin{array}{l}\text { Marital } \\
\text { Status }\end{array}$ & $0.143(1.20)$ & $0.233 *(1.84)$ & $\begin{array}{l}0.288^{* \star} \\
(2.31)\end{array}$ & $0.549 *(1.76)$ & $\begin{array}{l}0.784^{* *} \\
(2.32)\end{array}$ & $0.017(0.07)$ & $-0.195(-1.13)$ \\
\hline Living Area & & & $0.059(0.45)$ & $0.141(0.48)$ & $\begin{array}{l}1.334^{\star \star \star} \\
(2.99)\end{array}$ & $\begin{array}{l}0.528 * \star \\
(2.27)\end{array}$ & $0.359 *(1.90)$ \\
\hline Education & $\begin{array}{l}0.266^{\star \star} \\
(2.24)\end{array}$ & $0.057(00.43)$ & $0.060(0.46)$ & $0.419(1.40)$ & $-0.310(-0.67)$ & $0.192(0.77)$ & $0.249(1.52)$ \\
\hline Income & $-0.191(-1.01)$ & $0.344(1.42)$ & $0.172(0.72)$ & $0.421(0.92)$ & $-0.827(-0.83)$ & $-0.023(-0.07)$ & $-0.128(-0.45)$ \\
\hline $\begin{array}{l}\text { Social } \\
\text { Class }\end{array}$ & $\begin{array}{l}0.255^{\star \star \star} \\
(8.12)\end{array}$ & $\begin{array}{l}0.200 * \star \star \\
(6.57)\end{array}$ & $\begin{array}{l}0.280 * \star \star \\
(8.83)\end{array}$ & $\begin{array}{l}0.347 * \star \star \\
(4.03)\end{array}$ & $0.135(1.62)$ & $\begin{array}{l}0.223^{\star \star \star} \\
(3.55)\end{array}$ & $\begin{array}{l}0.115^{\star \star \star \star} \\
(2.76)\end{array}$ \\
\hline $\begin{array}{l}\text { Internet } \\
\text { Use }\end{array}$ & $0.003(0.09)$ & $0.106 *(1.79)$ & $\begin{array}{l}0.113^{\star \star} \\
(2.18)\end{array}$ & $0.112(1.16)$ & $0.041(0.36)$ & $0.005(0.09)$ & $0.000(0.00)$ \\
\hline $\begin{array}{l}\text { Friend } \\
\text { Interaction }\end{array}$ & $-0.009(-0.16)$ & $-0.036(-0.69)$ & $-0.049(-0.87)$ & $-0.082(-0.60)$ & $0.080(0.44)$ & $0.014(0.13)$ & $0.047(0.70)$ \\
\hline $\begin{array}{l}\text { Gathering } \\
\text { with } \\
\text { Relatives }\end{array}$ & $0.025(0.37)$ & $0.070(0.90)$ & $0.048(0.65)$ & $0.091(0.48)$ & $-0.120(-0.88)$ & $0.249 *(1.79)$ & $-0.043(-0.44)$ \\
\hline $\begin{array}{l}\text { Physical } \\
\text { Exercise }\end{array}$ & $\begin{array}{l}0.176 \text { } \\
(6.09)\end{array}$ & $\begin{array}{l}0.096 * \star \\
(2.45)\end{array}$ & & & & & \\
\hline
\end{tabular}

According to Table 3, the effect of positive psychology on mental health was at significant level for all physical exercise subgroups. However, the effect was the largest for older adults did physical exercise several times a month (coefficient $=0.196, p<$ 0.01). In addition, for older adults who exercise every day, the impact of positive psychology on mental health was the least (coefficient $=0,053, p<0.05$ ). This phenomenon indicates that medium level of physical exercise group achieved the best effect to improve mental health through positive psychology.

\section{Moderating Mechanism Analysis}

In this section, this study attempted to explore the moderating effect of individualism on the relationship linking positive psychology and mental health among the aged, and Table 4 reports the result. According to the moderating analysis results, individualism significantly strengthened the relationship between positive psychology and mental health of the elderly. After included the interaction item consisted of positive psychology and individualism, positive psychology still had a significant positive impact on mental health (coefficient $=0.112, p<0.01$ ), and the interaction item also had a significant positive impact on mental health (coefficient $=0.019, p<0.05$ ). What's more, individualism itself had no significant impact on mental health, which indicates that individualism and positive psychology formed no substitution or complementary effect with each other. 
Table 4

The Moderating Effect of Individualism

\begin{tabular}{|c|c|c|c|c|}
\hline Variable & Coefficient & S.E. & $\mathrm{t}$ & $p>|t|$ \\
\hline Positive Psychology & $0.112^{\star \star \star}$ & 0.012 & 9.39 & 0.000 \\
\hline Individualism & -0.039 & 0.030 & -1.31 & 0.191 \\
\hline Positive Psychology * Individualism & $0.019 * \star$ & 0.010 & 2.02 & 0.043 \\
\hline Age & $0.014 * \star \star$ & 0.005 & 2.85 & 0.004 \\
\hline Gender & 0.077 & 0.073 & 1.05 & 0.294 \\
\hline Marital Status & $0.192^{\star \star}$ & 0.087 & 2.21 & 0.023 \\
\hline Living Area & $0.265^{\star \star \star}$ & 0.090 & 2.94 & 0.003 \\
\hline Education & $0.160 *$ & 0.088 & 1.82 & 0.069 \\
\hline Income & 0.069 & 0.149 & 0.46 & 0.645 \\
\hline Social Class & $0.220 * \star \star$ & 0.022 & 10.18 & 0.000 \\
\hline Internet Use & 0.030 & 0.027 & 1.10 & 0.261 \\
\hline Friend Interaction & -0.023 & 0.038 & -0.60 & 0.548 \\
\hline Gathering with Relatives & 0.037 & 0.051 & 0.73 & 0.463 \\
\hline Physical Exercise & $0.141^{\star \star \star}$ & 0.023 & 6.04 & 0.000 \\
\hline Observations & 1,533 & & & \\
\hline
\end{tabular}

Figure 1 shows that individualism had a significant positive regulatory effect on the impact of positive psychology on the mental health of the elderly $\left(\beta_{3}=0.019, \mathrm{p}<0.05\right)$.

\section{Robustness Test}

Changing the measurement method is one of the effective means for robustness test. This study replaces OLS regression with logit regression for robustness test. If the conclusions of the two models are basically the same, the conclusion is robust and reliable. Table 5 shows that after logit model was used to run regression analysis, the results were consistent with previous regression models, so the results are robust 
Table 5

Results of Robustness Test

\begin{tabular}{|c|c|c|c|c|}
\hline Variable & Coefficient & S.E. & $\mathrm{t}$ & $p>|t|$ \\
\hline Positive Psychology & 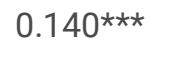 & 0.016 & 8.71 & 0.000 \\
\hline Individualism & $-0.070 *$ & 0.039 & -1.80 & 0.072 \\
\hline Positive Psychology * Individualism & $0.021^{\star}$ & 0.013 & 1.65 & 0.100 \\
\hline Age & 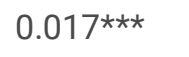 & 0.007 & 2.66 & 0.008 \\
\hline Gender & 0.100 & 0.094 & 1.07 & 0.287 \\
\hline Marital Status & $0.209 *$ & 0.112 & 1.87 & 0.062 \\
\hline Living Area & $0.407 \star \star \star$ & 0.118 & 3.46 & 0.001 \\
\hline Education & $0.266^{\star \star}$ & 0.115 & 2.31 & 0.021 \\
\hline Income & 0.056 & 0.194 & 0.29 & 0.775 \\
\hline Social Class & $0.278 * \star \star$ & 0.029 & 9.45 & 0.000 \\
\hline Internet Use & 0.024 & 0.035 & 0.67 & 0.501 \\
\hline Friend Interaction & -0.029 & 0.049 & -0.60 & 0.548 \\
\hline Gathering with Relatives & 0.028 & 0.066 & 0.43 & 0.666 \\
\hline Physical Exercise & $0.186^{\star \star \star}$ & 0.031 & 5.97 & 0.000 \\
\hline Observations & 1,533 & & & \\
\hline
\end{tabular}

\section{Discussion}

To explore the effects of positive psychology and individualism on mental health status of older adults in China, this study constructed OLS regression model based on the latest CGSS data conducted in 2017. Based on the analysis performed in this study, several main conclusions can be reached. First, positive psychology, demographic characteristics, socio-economic status, and health-related lifestyle factors, including age, marital status, living area, education background, social class, and physical exercise, are statistically significant and positively related to mental health status, while gender, income, internet use, friend interaction and gathering with relatives had no significant impact on mental health status of the elderly. Second, the effect of positive psychology on mental health for people in different living areas and with different physical exercise frequencies varies. Third, individualism significantly promotes the effect of positive psychology and mental health among older adults in China.

Based on existing studies [35-37], this study contributes to an understanding of the impacts of positive psychology and individualism on mental health status and the comparison of urban-rural and physical exercise disparities: (1) This study not only investigated the effects of positive psychology on the mental health of the elderly, but also introduced individualism as a moderating variable to analyze the impact mechanism. (2) Considering at present, most studies focus on intervention treatment through experimental method to explore the impact of positive psychology on mental health. This study uses questionnaire data to establish a measurement model for research. This is consistent with the conclusion confirmed by many studies, that is, positive psychology will enhance self-efficacy and personal resilience, and improve the level of mental health [38-41]. But the difference is that this study makes up for a research gap: what mechanism does positive psychology affect the mental health of the elderly? This study found that individualism plays an important regulatory role in it, promotes the positive impact of positive psychology on the mental health of the elderly. 
More studies are recognizing that as a general attitude towards political, economic, social, and religious behavior, individualism includes high evaluation of personal self-confidence, personal private life and respect for individuals, opposition to authority and all kinds of domination over individuals, which can enhance positive psychology [42, 43]. Moreover, one of the important symbols of modernity is the rise of individual and the emergence of individualism. Over the past 30 years of economic reform, great changes have taken place in the social culture of contemporary China. The concept of self-consciousness and individual rights has risen unprecedentedly. An individualistic society has come. ${ }^{44}$ This also shows that individualism is credible as a moderating variable.

According to previous studies, positive psychology is a powerful health capital, which can urge people to actively face the difficulties of life, have strong determination and courage to overcome difficulties, create a better life and pursue happiness [45, 46]. However, these studies did not realize the importance of individualism as an important cultural factor shaping the relationship between positive psychology and mental health. On the one hand, the individualistic cultural gene in western culture, especially the cultural concept of personality liberation and personal freedom promoted after the Renaissance and religious reform, is an internal force for the final formation of an institutionalized market economic order in western modern society. It also promotes individuals to bear market risks, create a better life and strengthen positive psychology [47]. On the other hand, from the late Qing Dynasty, Chinese society has experienced the impact of Western civilization. While destroying the traditional feudalistic ideas, the Enlightenment thinkers of China actively promote the rise of individualism in China, further advance the individual's positive psychology for the outlook on life [48, 49].

There are some limitations to this study that require mention. First, though the data used in this study are authoritative, the data are only limited in the year of 2007; thus, cross-sectional data may result in endogenous bias. Panel data could be used to provide more concrete evidence. Secondly, in addition to the differences between urban and rural areas, there are also great regional differences in China; however, due to the unavailability of data, this study failed to control for reginal factors. Third, the evaluation of health-related lifestyle factors is extremely complex, and how to measure it comprehensively has not reached a unified consensus. Therefore, the selected variables reflecting lifestyle factors may be far from complete.

Individuals in contemporary Chinese society have a very clear awareness of individual rights and have learned to express their wishes and claim their rights openly. However, due to the lack of public life, there is a lack of corresponding sense of obligation and responsibility. The positive psychology always stays at the individual level, and the collective positive psychological state has not been formed [50]. It is difficult to establish the collective positive psychology and improve mental health. On the other hand, with the development of the market economy, people have obtained unprecedented freedom in the private sphere and have a sense of personal rights. On the other hand, individuals were thrown out by various disintegrated communities, especially the elderly generation, have realized "self-centered", but they can't find an organic connection with public life and public community $[51,52]$. Therefore, they may encounter difficulties producing the positive psychology needed for mental health.

The purpose of this study is to show that for the elderly, individualism can promote the positive impact of positive psychology on mental health, but this individualism is not atomized individualism, but the consciousness of citizenship and individual rights under the proper protection of individual rights. This is also the reason why this study chose reproductive attitude as the representative variable of individualism. Because family planning once deeply restricted individuals' reproductive rights.

\section{Conclusion}

Through empirical analysis, this study drew the following conclusions: (1) Positive psychology could significantly increase the mental health of the elderly. In addition, by dividing samples into subgroups according to living area and physical exercise frequency, this study found that positive psychology had a significant impact on the mental health of both urban and rural elderly people at $1 \%$ significance level; this shows that the power of positive psychology can surpass the impact of the objective economic, cultural, and political gap caused by China's urban-rural dual structure on people and improve mental health. Meanwhile, for people who exercise several times a month, the mental health benefit of positive psychology is the largest. (2) Individualism promotes the relationship between positive psychology and mental health damage. 
The results suggest that positive psychology is significantly associated with a better mental health status for older Chinese residents, moderated by individualism, which is consistent with China's recent development of market economy, the improvement of the rule of law and the improvement of citizens' awareness of individual rights.

\section{Abbreviations}

CGSS

Chinese General Social Survey.

\section{Declarations}

\section{Acknowledgments}

The Author would like to acknowledge the CGSS team for providing the data.

\section{Author's contributions}

The author independently conceived the study, performed data analysis, and wrote the draft of the manuscript. The author approved the final version of the manuscript.

\section{Funding}

Not applicable.

\section{Availability of data and materials}

The CGSS datasets are publicly available at Renmin University of China Open Research Data platform (http://cgss.ruc.edu.cn/). Researchers can obtain these data after submitting a data use agreement to the CGSS team.

\section{Ethics approval and consent to participate}

No ethics approval was required for this study. The data were obtained from a publicly accessible database of the Chinese General Social Survey at Renmin University of China Open Research Data platform (http://cgss.ruc.edu.cn/) with a signed data use agreement.

\section{Consent for publication}

Not applicable.

\section{Competing interests}

The author declares that there is no competing interest.

\section{References}

1. Guo Y, Zhang C, Huang H, Zheng X, Pan XJ, Zheng J Z. Mental health and related influencing factors among the empty-nest elderly and the non-empty-nest elderly in Taiyuan, China: A cross-sectional study. Public Health 2016;141:210-217.

2. Zhong X, Wu D, Nie X, Xia J, Li M, Lei F, Mahendran R. Parenting style, resilience, and mental health of community-dwelling elderly adults in China. BMC Geriatr. 2016;16:1-8.

3. Cao W, Li L, Zhou X, Zhou C. Social capital and depression: Evidence from urban elderly in China. Aging Ment. Health 2015;19:418-429.

4. Li X, Xiao Z, Xiao S. Suicide among the elderly in mainland China. Psychogeriatrics 2009;9:62-66. 
5. Antoine P, Dauvier B, Andreotti E, Congard A. Individual differences in the effects of a positive psychology intervention: Applied psychology. Pers. Individ. Differ. 2018;122:140-147.

6. Bar-On R. Emotional intelligence: An integral part of positive psychology. South Afr. J. Psychol. 2010;40:54-62.

7. Held BS. The tyranny of the positive attitude in America: Observation and speculation. J. Clin. Psychol. 2002;58:965-991.

8. Callahan WA. Dreaming as a critical discourse of national belonging: China Dream, American Dream and world dream. Nations Natl. 2017;23:248-270.

9. Kristjánsson K. Positive psychology, happiness, and virtue: The troublesome conceptual issues. Rev. Gen. Psychol. 2010;14:296-310.

10. Lazarus RS. Does the positive psychology movement have legs? Psychol. Inq. 2003;14:93-109.

11. Slade M. Mental illness and well-being: The central importance of positive psychology and recovery approaches. BMC Health Serv. Res. 2010;10:1-14.

12. Martin MW. Happiness and virtue in positive psychology. J. Theory Soc. Behav. 2007;37:89-103.

13. Meyers MC, van Woerkom M, Bakker AB. The added value of the positive: A literature review of positive psychology interventions in organizations. Eur. J. Work Organ. Psychol. 2013;22:618-632.

14. Sandage SJ, Hill PC. The virtues of positive psychology: The rapprochement and challenges of an affirmative postmodern perspective. J. Theory Soc. Behav. 2001;31:241-260.

15. Sin NL, Lyubomirsky S. Enhancing well-being and alleviating depressive symptoms with positive psychology interventions: A practice-friendly meta-analysis. J. Clin. Psychol. 2009;65:467-487.

16. Vazquez C, Duque A, Blanco I, Pascual T, Poyato N, Lopez-Gomez I, Chaves C. CBT and positive psychology interventions for clinical depression promote healthy attentional biases: An eye-tracking study. Depress. Anxiety 2018;35:966-973.

17. Proyer RT, Gander F, Wellenzohn S, Ruch W. Positive psychology interventions in people aged 50-79 years: Long-term effects of placebo-controlled online interventions on well-being and depression. Aging Ment. Health 2014;18:997-1005.

18. Veenhoven R. Social conditions for human happiness: A review of research. Int. J. Psychol. 2015;50:379-391.

19. Song R, Sun N, Song X. The efficacy of psychological capital intervention (PCl) for depression from the perspective of positive psychology: A pilot study. Front. Psychol. 2019;10:1816.

20. Christopher JC, Hickinbottom S. Positive psychology, ethnocentrism, and the disguised ideology of individualism. Theory Psychol. 2008;18:563-589.

21. Wood AM, Joseph S. The absence of positive psychological (eudemonic) well-being as a risk factor for depression: A ten year cohort study. J. Affect. Disord. 2010;122:213-217.

22. Boettke PJ. Individuals and institutions. Crit. Rev. 1990;4:10-26.

23. Koch BJ, Koch PT. Collectivism, individualism, and outgroup cooperation in a segmented China. Asia Pac. J. Manag. 2007;24:207-225.

24. Joshanloo M, Jarden A. Individualism as the moderator of the relationship between hedonism and happiness: A study in 19 nations. Pers. Individ. Differ. 2016:94;149-152.

25. Cabanas E. Positive psychology and the legitimation of individualism. Theory Psychol. 2018;28:3-19.

26. Brown D. Mastery of the mind east and west: Excellence in being and doing and everyday happiness. Ann. N.Y. Acad. Sci. 2009;1172:231-251.

27. Sundararajan L. Happiness donut: A Confucian critique of positive psychology. J. Theor. Philos. Psychol. 2005;25:35-60.

28. Chitra T, Karunanidhi S. The impact of resilience training on occupational stress, resilience, job satisfaction, and psychological well-being of female police officers. J. Police Crim. Psychol. 2021;36:8-23.

29. Diener E. What is positive about positive psychology: The curmudgeon and Pollyanna. Psychol. Inq. 2003;14:115-120.

30. Donaldson SI, Dollwet M, Rao MA. Happiness, excellence, and optimal human functioning revisited: Examining the peerreviewed literature linked to positive psychology. J. Posit. Psychol. 2015;10:185-195.

31. Waterman AS. Individualism and interdependence. Am. Psychol. 1981;36:762-773. 
32. Lomas T, Ivtzan I. Second wave positive psychology: Exploring the positive-negative dialectics of wellbeing. J. Happiness Stud. 2016;17:1753-1768.

33. O'Brien C. Sustainable happiness and well-being: Future directions for positive psychology. Psychology 2012;3:1196-1201.

34. Jacobson L. The family as producer of health-an extended Grossman model. J. Health Econ. 2000;19:611-637.

35. Chida Y, Steptoe A. Positive psychological well-being and mortality: A quantitative review of prospective observational studies. Psychosom. Med. 2008;70:741-756.

36. Aspinwall LG, Tedeschi RG. The value of positive psychology for health psychology: Progress and pitfalls in examining the relation of positive phenomena to health. Ann. Behav. Med. 2010;39:4-15.

37. Carr A, Finnegan L. The say 'yes' to life (SYTL) program: A positive psychology group intervention for depression. J. Contemp. Psychother. 2015;45:109-118.

38. Celano CM, Gomez-Bernal F, Mastromauro CA, Beale EE, DuBois CM, Auerbach RP, Huffman JC. A positive psychology intervention for patients with bipolar depression: a randomized pilot trial. J. Ment. Heal. 2020;29:60-68.

39. Chaves C, Lopez-Gomez I, Hervas G, Vazquez C. A comparative study on the efficacy of a positive psychology intervention and a cognitive behavioral therapy for clinical depression. Cogn. Ther. Res. 2017;41:417-433.

40. Fredrickson BL. The value of positive emotions: The emerging science of positive psychology is coming to understand why it's good to feel good. Am. Scientist 2003;91:330-335.

41. Wood AM, Tarrier N. Positive clinical psychology: A new vision and strategy for integrated research and practice. Clin. Psychol. Rev. 2010;30:819-829.

42. Binkley S. Happiness, positive psychology and the program of neoliberal governmentality. Subjectivity 2011;4:371-394.

43. Becker D, Marecek J. Dreaming the American dream: Individualism and positive psychology. Soc. Personal. Psychol. Compass 2008;2:1767-1780.

44. Steele LG, Lynch SM. The pursuit of happiness in China: Individualism, collectivism, and subjective well-being during China's economic and social transformation. Soc. Indic. Res. 2013;114:441-451.

45. Danner DD, Snowdon DA, Friesen WV. Positive emotions in early life and longevity: findings from the nun study. J. Pers. Soc. Psychol. 2001;80:804-813.

46. Gable SL, Haidt J. What (and why) is positive psychology? Rev. Gen. Psychol. 2005;9:103-110.

47. Papadopoulos C, Foster J, Caldwell K. 'Individualism-collectivism'as an explanatory device for mental illness stigma. Community Ment. Health J. 2013;49:270-280.

48. Rego A, Cunha MP. How individualism-collectivism orientations predict happiness in a collectivistic context. J. Happiness Stud. 2009;10:19-35.

49. Ryff CD. Psychological well-being in adult life. Curr. Dir. Psychol. 1995;4:99-104.

50. Dubois N, Beauvois JL. Normativeness and individualism. Eur. J. Soc. Psychol. 2005;35:123-146.

51. Cabanas E. Rekindling individualism, consuming emotions: Constructing "psytizens" in the age of happiness. Cult. Psychol. 2016;22:467-480.

52. Warr P. A study of psychological well-being. Br. J. Psychol. 1978;69:111-121.

\section{Figures}




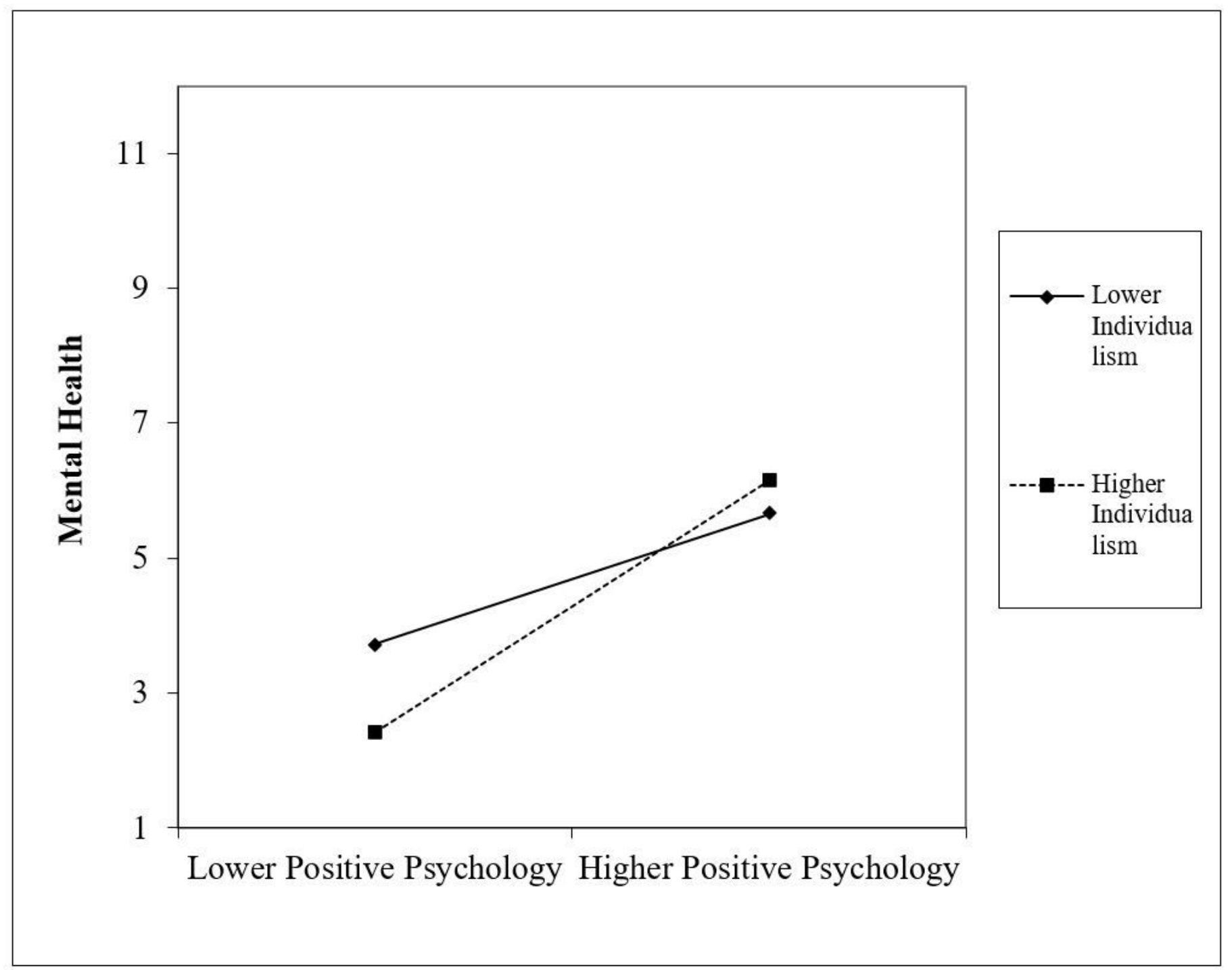

Figure 1

The Moderating Effect of Individualism 